\title{
Predicting the mating system from phenotypic correlations between life-history and sperm quality traits in the Alpine whitefish Coregonus zugensis
}

\author{
Geir Rudolfsen • Rudolf Müller • Davnah Urbach • \\ Claus Wedekind
}

Received: 15 December 2006 /Revised: 2 July 2007 / Accepted: 24 August 2007 / Published online: 9 October 2007

(C) Springer-Verlag 2007

\begin{abstract}
The mating behavior and reproductive strategies of Alpine whitefish like Coregonus zugensis (Nüsslin) are poorly understood, probably because they spawn in deep water where direct observations are difficult. In this study, we interpret life-history and sperm quality traits of fish that we caught from their spawning place. We found that males invest heavily into gonadal tissue (up to $5.6 \%$ of their body weight), which is, in comparison to other fish, consistent with external fertilization, distinct pairing and moderate to high communal spawning, or no pairing and low to moderate communal spawning. Sperm competition theory and recent experimental studies on other salmonids predict that males optimize ejaculate characteristics in relation to the costs of sperm and the level of competition they have to expect: dominant males are predicted to invest less into ejaculate quality and to have slower spermatozoa than subdominant males. We found that spermatozoa of older males are slower than those of younger males. Moreover, older males have larger breeding tubercles, a secondary sexual trait that has, in some previous studies, been found
\end{abstract}

Communicated by T. Bakker

G. Rudolfsen

Department of Evolution and Ecology, Institute of Biology,

University of Tromsø,

Tromsø, Norway

\section{R. Müller $\cdot$ C. Wedekind}

Swiss Federal Institute of Aquatic Science

and Technology (Eawag),

6047 Kastanienbaum, Switzerland

D. Urbach $\cdot$ C. Wedekind $(\square)$

Department of Ecology and Evolution, Biophore,

University of Lausanne,

1015 Lausanne, Switzerland

e-mail: claus.wedekind@unil.ch to be linked to good condition and to good genetic quality. Our results suggest that $C$. zugensis has age-linked reproductive strategies, that multimale spawning is common, i.e., that sperm competition plays a significant role, and that older males are on average dominant over younger males at the spawning place.

Keywords Mating system · Sperm competition · Sperm velocity · Male mating strategies · Salmonids · Good genes sexual selection

\section{Introduction}

The indigenous species flock of Alpine whitefish (Coregonus sp.) consists of many distinct populations that live in lakes of the prealpine region of central Europe. Various populations have been described that differ in life history, morphology, or genetics and that should, therefore, be viewed as "management units" (Douglas and Brunner 2002). Like many other salmonids, Alpine whitefish are exploited by commercial and recreational fisheries, with yields of up to $10 \mathrm{~kg} / \mathrm{ha}$ in oligotrophic lakes (Müller 1990). As a consequence, fish older than 4+ years are rarely found, although the natural life-history seems to allow for much higher age. In addition, like many other salmonids, whitefish populations are typically managed by supportive breeding in hatcheries. Spawners (usually at the age of $2+$ to $4+$ years) are caught from the wild, their gametes stripped for artificial fertilization and embryos reared until some early stage (usually yolk-sac fry) at which they are released into the wild.

The reproductive success of spawners in hatcheries is not likely to reflect their expected success at the natural spawning place, i.e., the more or less random mating in hatcheries largely circumvent intra- and inter-sexual selec- 
tion that can be expected in the wild (Andersson 1994). Artificial fertilization may, therefore, change the genetics of wild populations as compared to natural reproduction, and it would be important to know the long-term evolutionary consequences of this change (Wedekind et al. 2001, 2007b; Wedekind 2002; Wedekind and Müller 2004; Rudolfsen et al. 2005; Pitcher and Neff 2006). However, not much is known about the natural mating system of Alpine whitefish except that they are external fertilizers with no parental care, that they typically aggregate for spawning once a year for a few weeks, and that they have so-called breeding tubercles, i. e., secondary sexual traits that are developed shortly before breeding season and that fall off immediately afterwards (Wiley and Collette 1970; Wedekind et al. 2007a).

The benthopelagic and iteroparous small-type Alpine whitefish Coregonus zugensis is one of these species that spawn in large aggregations during the few weeks in winter and in depths below $25 \mathrm{~m}$. In such aggregations of spawners, multimale spawnings can be expected to be frequent (Wedekind 1996; Taborsky 1998; Kokko and Rankin 2006). We, therefore, assume that sperm competition theory can be applied to this species, i.e., that by examining sperm characteristics and correlated life-history traits, we may be able to make testable predictions about dominance hierarchies of males at their natural spawning place.

Recent theoretical and empirical work has lead to a farreaching understanding of sperm competition, i.e., of the competition of different males' sperm over the fertilization of the same eggs (reviews in Birkhead and Møller 1998; Wedell et al. 2002; Snook 2005). Under natural conditions, ejaculation characteristics can be expected to be determined by a trade-off of the costs of sperm (Gage and Cook 1994; Olsson et al. 1997) and the potential benefits. These benefits are dependent on the perceived quality of the mating partner, whether there are competitors to be expected, or whether the raffle is loaded or fair (e.g., (Taborsky 1998; Vladic and Jarvi 2001; Vladic et al. 2002; Evans et al. 2003; Pizzari et al. 2003; Burness et al. 2004; Gage et al. 2004; Pound and Gage 2004; Zbinden et al. 2004; Kilgallon and Simmons 2005; Ramm et al. 2005; Preston and Stockley 2006; Rudolfsen et al. 2006; Stoltz and Neff 2006). Some of these empirical studies have been done with externally fertilizing fish (see also references below). They provide much support for the prediction that, in such cases, subdominant males invest more into ejaculation quality than dominant males (Parker 1990; Ball and Parker 1996, 2000). One recent study demonstrates, for example, that experimentally induced dominance leads to reduced sperm velocity within only 4 days in the group spawning Arctic charr (Salvelinus alpinus; Rudolfsen et al. 2006).

In this study, we test in $C$. zugensis whether there is variation in the sperm characteristics that is consistent with age- or size-linked optimization strategies. We also test the alternative hypothesis that reduced sperm velocity in older males is due to age-linked conditional or genetic problems (Gomendio et al. 2000; Gage et al. 2006). We, therefore, test whether age or sperm characteristics are linked to potential quality indicators like body condition (Bolger and Connoly 1989) or the size of breeding tubercles.

\section{Materials and methods}

We drew samples from large catches taken by professional fishermen. They caught the fish with gill nets around the start of the breeding season (Nov 20th) and on four different days between December 5 and 18 during the same breeding season in Lake Lucerne (central Switzerland, Fig. 1). The nets were always set at about the same spawning place in $20-40-\mathrm{m}$ depth in the evenings and retrieved early the next morning. Our samples of live fish were immediately transported to the laboratory where males and females were stripped within the next 2 to $3 \mathrm{~h}$. The mature males caught at the first sampling date were classified into those that had milt and seemed to be ready to spawn ("spawners") and males of which no milt could yet be stripped ("prespawners"). Dissection of the gonads confirmed that prespawners would soon produce milt. From the other four catches during the breeding season, we randomly selected mature males (Table 1) and stripped their milt by applying gentle bilateral abdominal pressure (after killing them with a sharp blow on their head and carefully drying the genital pore to avoid accidental activation of the sperm). Until further use, the milt was kept for a maximal $2 \mathrm{~h}$ in a closed Petri dish at low temperature (about $5^{\circ} \mathrm{C}$ ). We determined the total amount of milt that could be stripped (to the nearest $10 \mu \mathrm{l}$ ), and the spermatocrit value as an approximation to sperm cell density in the milt. For the latter, a $10-\mu 1$ sample of homogenized milt was collected in a capillary tube and centrifuged for $195 \mathrm{~s}$ at $11,500 \mathrm{rpm}$. We then used aliquots of milt for sperm velocity measurements.

We took the following measurements of all males: total body length, body weight, gonad weight, and age. Age was determined by counting the annual rings on scales sampled below the dorsal fin near the lateral line (Rubin and Perrin 1990). Plaster casts were taken to later determine a standard measure of the size of the breeding tubercles (Wiley and Collette 1970). For each fish, we determined the average height of the 16 largest tubercles that could be found near the lateral line above the anal fin or below the dorsal fin (depending on plaster cast quality). We chose this standard measure to keep the influence of possible measurement error minimal and to allow for later comparison to previous 
Fig. 1 Schematic map of Switzerland and Lake Lucerne (in$s e r t$ ). The spawning place and sampling location is about $1.5 \mathrm{~km}$ south of the shore of Meggen at around 20-40 m depth

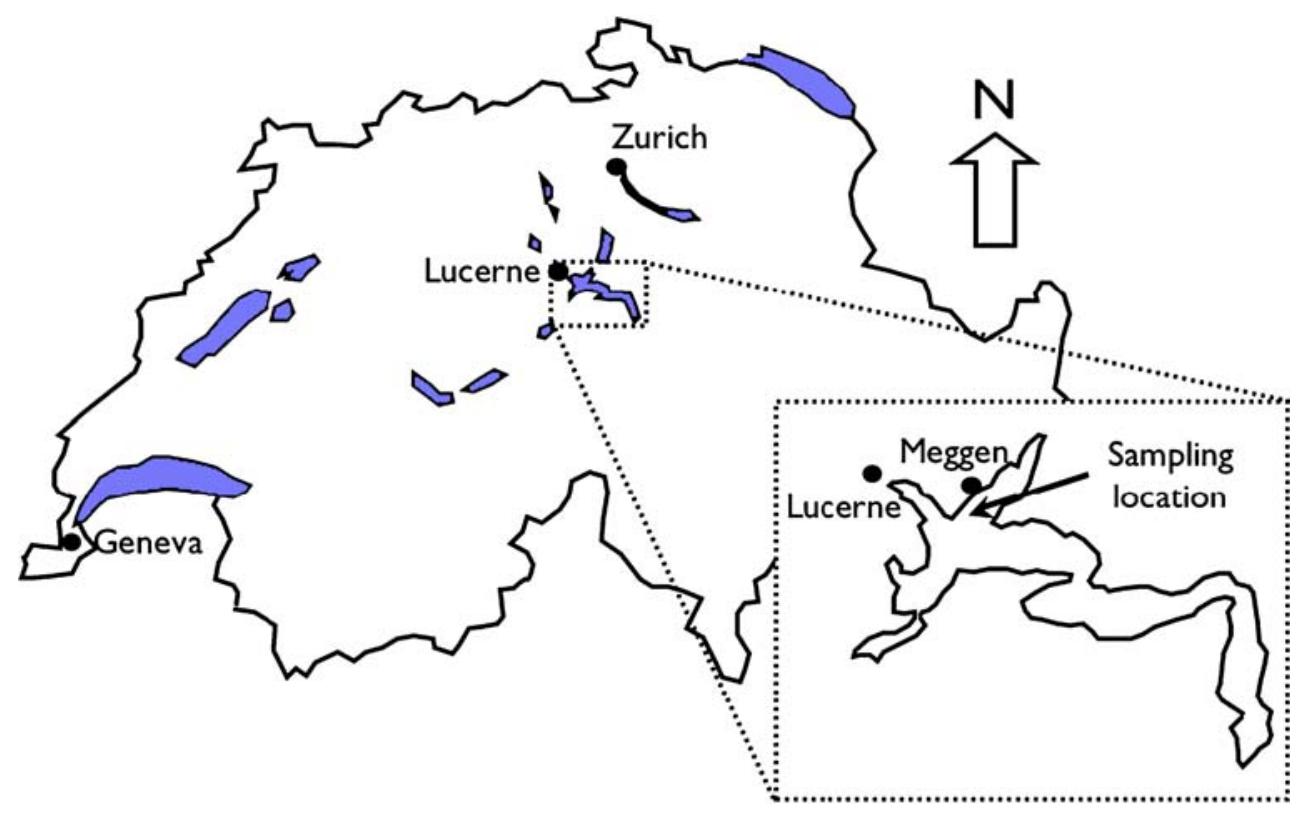

studies that used this measure. See detailed methods in Wedekind et al. (2001).

We measured overall male investment into reproduction with the weight of gonads relative to total body weight (=gonadosomatic index, GSI). We calculated the GSI as GSI= (the weight of the milt that could be stripped plus the weight of remaining gonad tissue)/(total body weight). The GSI should be carefully interpreted in fish that are caught during the spawning season, because a high GSI can reveal a high male investment into sperm production or, alternatively, late arrival at the spawning place or other reasons why a given male has yet spent less sperm than other fish until the moment of sampling. To circumvent this potential problem, we analyzed not only males that were caught during the spawning season but also males that were caught at the very beginning of the spawning season and had mature gonads but had not released milt yet. See Tomkins and Simmons (2002) for further discussion of this measure. The condition factor $K$ was determined for all males as $K=$ body weight/body length ${ }^{b}$, with $b$ being the slope of the regression of $\log$ (weight) on $\log$ (length; Bolger and Connoly 1989). In this study, $b=3.0$.

Sperm velocity was measured by placing an aliquot $(0.12 \mu \mathrm{l})$ of undiluted milt on a cooled microscope slide (at $5.6^{\circ} \mathrm{C}$ ) with a fixed cover glass and a $20-\mu \mathrm{m}$ deep chamber (volume of $5 \mu \mathrm{l}$ ). The sperm were activated by adding $4.5 \mu$ lake water that had been adjusted to approximately $5.6{ }^{\circ} \mathrm{C}$. A video camera that was mounted on a phasecontrast microscope with a $10 \times$ objective recorded sperm motion at $50 \mathrm{~Hz}$ frequency. We analyzed the recordings later with a computer-assisted sperm analysis program (CEROS version 12: Hamilton Thorne Research, Beverly, MA, USA, see Rudolfsen et al. (2005) for further details about the method and for specifications of the equipment). This kind of sperm analysis provides the average path velocity (VAP), the straight line velocity (VSL), and the curvilinear velocity (VCL) of the sperm. All recordings were analyzed for 25 video frames (i.e., $0.5 \mathrm{~s}$ ) after intervals of $10 \mathrm{~s}$ each during the first minute after sperm

Table 1 Number, age, and biometry (means \pm s.e.) of males sampled on various dates at the beginning and during the breeding season

\begin{tabular}{|c|c|c|c|c|}
\hline Catch date (sample) & Number $_{\text {young: }}$ Number ${ }_{\text {old }}$ & Body weight (g) & Body length (mm) & $\operatorname{GSI}(\%)$ \\
\hline Nov 20th (prespawners) & 25: 11 & $74.0 \pm 3.0$ & $224.5 \pm 2.4$ & $3.2 \pm 0.2$ \\
\hline Nov 20th (spawners) & 20: 9 & $81.4 \pm 3.3$ & $230.0 \pm 3.1$ & $3.4 \pm 0.2$ \\
\hline December 5 & 18: 4 & $78.7 \pm 2.5$ & $229.5 \pm 2.5$ & $3.7 \pm 0.2$ \\
\hline December 11 & 12: 6 & $77.3 \pm 2.7$ & $231.3 \pm 2.6$ & $3.5 \pm 0.3$ \\
\hline December 12 & $5: 3$ & $83.2 \pm 4.1$ & $233.0 \pm 4.0$ & $3.6 \pm 0.2$ \\
\hline December 18 & 15: 1 & $75.3 \pm 3.0$ & $229.3 \pm 2.9$ & $3.1 \pm 0.3$ \\
\hline
\end{tabular}

On the first catch date, mature males were classified as "prespawners" if no milt could be stripped, and "spawners" otherwise. The other four samples taken later were used for sperm analyses and for breeding experiments. 
activation. We repeated the procedure at least once for most males and used the mean sperm velocity after each $10 \mathrm{~s}$ interval for further analyses. The repeatability of the measurements at the different time intervals was high (for VAP: $0.54<r<0.74, p$ always $<0.0001$; VSL: $0.58<r<0.73$, $p$ always $<0.0001$, VCL: $0.37<r<0.76, p$ always $<0.006$ ).

Parametric statistical procedures (two-sample $t$ tests, one-factor ANOVAs, and repeated-measures ANOVAs with two factors) were used after graphical examination suggested that the assumptions of the respective statistical models were met. Otherwise non-parametric statistics (Wilcoxon two-sample tests) were used. All analyses were done with the Jmp statistical package (JMP 1989-2005), and all $p$ values are two tailed. Due to technical problems spermatocrit could not be measured for 14 males.

\section{Results}

Male samples taken at the start of the spawning season

At the first sampling date, we caught in total 65 males of which 36 (55\%) had fully developed gonads but no milt yet ("prespawners"), while all other males already had milt ("spawners"). Prespawners and spawners did not significantly differ in age $\left(\chi^{2}=0.002, p=0.97\right)$ nor condition factor $K\left(t_{63}=1.4, p=0.16\right)$; spawners were, although not significantly, slightly larger $\left(t_{63}=1.5, p=0.13\right)$ and heavier $\left(t_{63}=1.7, p=0.10\right)$ than prespawners.

The age distribution of prespawners was: $25 \times 2+(2+=$ between 2 and 3 years old), $10 \times 3+$, and one $4+$. Classes $3+$ and $4+$ were grouped to "old" and compared to the "young" $2+$ males. The GSI of prespawners ranged from 1.1 to $4.6 \%$ and was positively linked to age $\left(t_{24}=2.4, p=0.026\right)$, condition factor $K(r=0.57, n=26, p=0.002)$, body length $(r=0.46, n=$ 26, $p=0.017)$, and body weight $(r=0.55, n=26, p=0.004)$. The GSI of spawners ranged from 2.3 to $5.1 \%$ and was not significantly different from one of the prespawners $\left(t_{44}=0.9\right.$, $p=0.37)$. Older males were heavier and larger $\left(t_{34}\right.$ always $>$ 4.0, $p$ always $<0.0003$ ), but their condition factor $K$ was not significantly higher $\left(t_{34}=1.0, p=0.32\right)$.

Male samples taken during spawning season

During the breeding season we sampled in total 64 males on 4 days (Table 1 ). The age distribution was: $50 \times 2+, 13 \times$ $3+$, and one $4+$. Classes $3+$ and $4+$ were again grouped to "old." Older males were heavier $\left(t_{62}=2.4, p=0.02\right)$, were larger $\left(t_{62}=2.0, p=0.05\right)$, and had larger breeding tubercles $\left(t_{62}=2.4, p=0.02\right)$. However, age was not significantly linked to condition factor $K\left(t_{62}=1.0, p=0.32\right)$, GSI $\left(t_{62}=\right.$ $1.9, p=0.07)$, or spermatocrit level $\left(t_{48}=-0.1, p=0.90\right)$. The age distribution was not significantly different between the different catch dates (Table $1 ; \chi_{3}^{2}=5.4, p=0.14$ ). The samples from the 4 days did also not significantly differ in average body weight, body length, GSI, or the average spermatocrit levels (Table 1; $F$ always $<1.0, p$ always $>$ $0.05)$. The GSI ranged from 1.3 to $5.6 \%$.

\section{Sperm velocity}

We had measured sperm velocity after six consecutive $10 \mathrm{~s}$ intervals each. We, therefore, used a repeated measures ANOVA to test whether sperm velocity was influenced by male age and included sampling date as a factor to account for possible changes over time. Male age is significantly linked to sperm velocity in two ways: older males have overall lower sperm velocity (significant male effect in Table 2, see also Fig. 2), and the decline in sperm velocity over the first minute after activation is more pronounced in young males than in old males (the significant withinsubject interaction terms in Table 2, see Fig. 2). The date in the season does not seem to influence average sperm velocity (non-significant between-subject effects of date in

Table 2 The effect of male age and sampling date on sperm speed as measured in $10 \mathrm{~s}$ intervals during the first minute after sperm activation

\begin{tabular}{|c|c|c|c|c|c|c|c|c|c|}
\hline & \multicolumn{3}{|l|}{ VAP } & \multicolumn{3}{|l|}{ VSL } & \multicolumn{3}{|l|}{ VCL } \\
\hline & $\mathrm{F}$ & d.f. & $\mathrm{P}$ & $\mathrm{F}$ & d.f. & $\mathrm{P}$ & $\mathrm{F}$ & d.f. & $\mathrm{P}$ \\
\hline \multicolumn{10}{|l|}{ Between subjects } \\
\hline Male age & 5.3 & 1,51 & 0.03 & 4.8 & 1,51 & 0.03 & 4.1 & 1,51 & 0.05 \\
\hline Date & 0.8 & 3,51 & 0.51 & 0.5 & 3,51 & 0.68 & 1.1 & 3,51 & 0.37 \\
\hline Age $\times$ date & 2.3 & 3,51 & 0.09 & 2.4 & 3,51 & 0.08 & 1.9 & 3,51 & 0.15 \\
\hline \multicolumn{10}{|c|}{ Within subjects (repeated measurements on individual sperm samples) } \\
\hline Time & 246.2 & 5,47 & $<0.0001$ & 144.3 & 5,47 & $<0.0001$ & 271.8 & 5,47 & $<0.0001$ \\
\hline Time $\times$ age & 3.6 & 5,47 & 0.007 & 1.5 & 5,47 & 0.22 & 5.3 & 5,47 & 0.0006 \\
\hline Time $\times$ date & 2.0 & 15,130 & 0.02 & 1.8 & 15,130 & 0.05 & 2.4 & 15,130 & 0.004 \\
\hline Time $\times$ age $\times$ date & 2.7 & 15,130 & 0.001 & 1.9 & 15,130 & 0.03 & 2.7 & 15,130 & 0.001 \\
\hline
\end{tabular}

Sperm speed was determined as mean average path velocity (VAP), mean straight line velocity (VSL), and mean curvilinear velocity (VCL). For within-subject analyses we used the multivariate $F$ tests or Wilk's lambda (when a factor had more than two levels) 


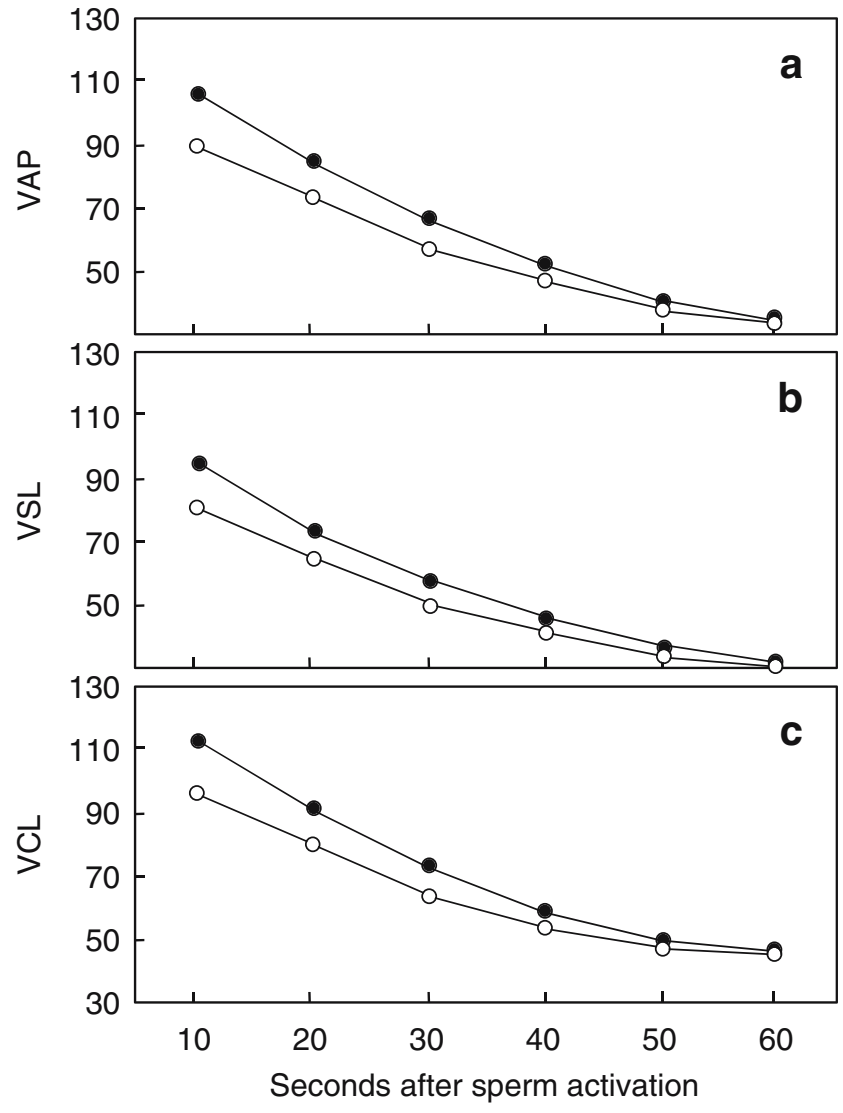

Fig. 2 Average sperm velocity $(\mu \mathrm{m} / \mathrm{sec})$ of young (closed symbols, $n=$ 45) and old males (open symbols, $n=14$ ) during the first minute after activation. The figure give (a) VAP, (b) VSL and (c) VCL. See Table 2 for statistics

Table 2), but date is linked to how sperm velocity declines over the first minute after activation (significant withinsubject effects of date in Table 2).

Neither male weight, nor length, nor condition factor $K$ was significantly linked to any sperm measurement averaged over the first minute (VAP, VSL, and VCL: $-0.27<r<$ $-0.11, n=59, p$ always $>0.05)$. The same was true within each age class ( $p$ always $>0.05)$. Breeding tubercles size was also not significantly correlated to any measure of sperm velocity ( $r$ always $<0.11, p$ always $>0.44$ ).

\section{Discussion}

The fact that $C$. zugensis spawns in large aggregations inevitably leads to some degree of sperm competition. Accordingly, we observed that males invest heavily into their gonads. Stockley et al. (1997) found in their metaanalysis on fish of various families that the GSI correlates positively with the level of sperm competition. Compared to these other fish, the GSIs of up to $5.6 \%$ that we found in C. zugensis corresponds to a level of sperm competition of three or four on the five-point scale of Stockley et al.
(1997). This is consistent with external fertilization, distinct pairing, and moderate to high communal spawning, or alternatively, no pairing and low to moderate communal spawning. C. zugensis, therefore, seems to be a species for which sperm competition theory is applicable. This theory makes clear predictions about the relative investment of dominant and subdominant males into ejaculate quality, and many empirical studies confirm these predictions (references cited in the Introduction). One specific prediction is that dominant males, which are less likely to face sperm competition and are usually positioned better during spawning invest relatively less into sperm quality than subdominant males. We, therefore, analyzed sperm quality to predict the dominance hierarchies at the spawning place. We found that older males have on average slower sperm than younger males.

There are competing hypotheses that could potentially explain low sperm velocity of older males. As described above (see also "Introduction"), low sperm velocity could be a consequence of an adaptive cost-benefit optimization that takes dominance at the spawning ground into account. Alternatively, low sperm velocity could be a sign of low body condition or low genetic quality of older males (Hosken et al. 2003; Locatello et al. 2006). However, effects linked to senescence are unlikely at the ages we studied. Without the current fishing pressure, C. zugensis could grow much older than $4+$ years, i.e., the "older" males in our sample can be considered as only middle-aged in the life history of the species (Müller 1990; Richard et al. 2005). Moreover, we found that older males show no signs of conditional or genetic problems: Older males were on average larger and had stronger breeding tubercles than young males. They also started the breeding season with larger GSI, i.e., they were able to invest more than younger males into their relative gonad weight (Hellriegel and Blanckenhorn 2002), and their condition factor $K$ was not significantly lower than that of younger males at any time during the spawning season. Recently, Wedekind et al. 2007a tested the viability of embryos sired by young and old males of $C$. zugensis and found no significant negative effect of sire age on offspring viability.

Secondary sexual traits are often quality indicators that are linked to male condition and/or genetic quality (Møller and Alatalo 1999; Neff and Pitcher 2005). In the case of whitefish, the secondary sexual traits are breeding tubercles, i.e., little horny structures (Wiley and Collette 1970). In a previous studies we found that the size of breeding tubercles can sometimes be a significant predictor of offspring survival in whitefish (Wedekind et al. 2001, 2007a). In roach (Rutilus rutilus), another iteroparous group spawner with external fertilization, the size of breeding tubercles is positively linked to male dominance (Kortet et al. 2004a) and male size (Wedekind 1992), but not 
significantly to sperm velocity (Kortet et al. 2004c) nor offspring viability (Kortet et al. 2004b). Although the function of breeding tubercles is still not fully clear yet (see also Müller and Ward 1995; Wedekind et al. 2007a), the fact that, in the present study, older males had significantly larger tubercles than younger males suggests again that the reduced sperm velocity of older males is not due to a reduced male health and vigor.

Our study cannot fully distinguish age from size effects, because age and size is usually linked in fish like the whitefish. However, when we tested within each age class, we found no significant effect of fish size, weight, or condition factor $K$ on sperm velocity. This is in constrast to recent findings in $C$. fatioi where male size correlated negatively with sperm velocity as measured $10 \mathrm{~s}$ after activation (Urbach et al. 2007). Our findings suggest that in $C$. zugensis, other factors that are expected to be linked to age (e.g., male experience) may affect the dominance hierarchies among the males on a natural spawning place.

Taken together, our findings suggest that in the case of our study population, older males strategically invest into their sperm quality according to the expected costs and benefits. In the light of sperm competition theory, the most parsimonious explanation for such a strategic investment is that older males are on average more dominant at the spawning place than younger males, although it is still not fully clear whether the various "spend and safe" strategies (Gage 2003) that can be observed in many salmonids do indeed maximize lifetime reproductive success (Figenschou et al. 2007). Further studies therefore need to examine the adaptive value of the various strategies males are playing at the spawning place.

Salmonids are economically important and therefore heavily managed wherever they occur. It is certainly a safe assumption that the various selection pressures at the natural spawning ground influence the evolution of current populations. An understanding of these forces is necessary for an adaptive population management that optimizes the long-term viability of populations (Wedekind 2002, 2003; Campton 2004). Our results suggest that older males play a dominant role at the natural spawning ground. This is usually in sharp contrast to the artificial fertilization programs in hatcheries, where milt of the various males is mostly used arbitrarily and in the quantities it can be stripped. Such protocols not only override any natural male reproductive advantages that are linked to dominance (Wedekind et al. 2007b), but they may even lead to a reproductive disadvantage of older and more dominant males because of their reduced sperm velocity. Males that would be successful at the natural spawning place may, therefore, be underrepresented as sires of hatchery-born fish.
Acknowledgements We thank N. Hofer, A. Hofer, and J. Muggli for catching the fish, A. Steffen, M. Bia, and U. Lauterburg for technical assistance, I. Folstad for support, T. Bakker, I. Folstad, A. Jacob, and the anonymous reviewers for constructive comments on the manuscript, and the Swiss National Science Foundation for financial support. The study complies with the current Swiss laws.

\section{References}

Andersson M (1994) Sexual selection. Princeton University Press, Princeton

Ball MA, Parker GA (1996) Sperm competition games: external fertilization and 'adaptive' infertility. J Theor Biol 180:141-150

Ball MA, Parker GA (2000) Sperm competition games: a comparison of loaded raffle models and their biological implications. J Theor Biol 206:487-506

Birkhead TR, Møller AP (1998) Sperm competition and sexual selection. Academic, London

Bolger T, Connoly PL (1989) The selection of suitable indices for the measurement and analysis of fish condition. J Fish Biol 34:171-182

Burness G, Casselman SJ, Schulte-Hostedde AI, Moyes CD, Montgomerie R (2004) Sperm swimming speed and energetics vary with sperm competition risk in bluegill (Lepomis macrochirus). Behav Ecol Sociobiol 56:65-70

Campton DE (2004) Sperm competition in salmon hatcheries: The need to institutionalize genetically benign spawning protocols. Trans Am Fish Soc 133:1277-1289

Douglas MR, Brunner PC (2002) Biodiversity of Central Alpine Coregonus (Salmoniformes): Impact of one-hundred years of management. Ecol Appl 12:154-172

Evans JP, Pierotti M, Pilastro A (2003) Male mating behavior and ejaculate expenditure under sperm competition risk in the eastern mosquitofish. Behav Ecol 14:268-273

Figenschou L, Rudolfsen G, Folstad I (2007) Female Arctic charr do not show apparent benefits from exposing their eggs to sperm from dominant males. J Fish Biol 71:284-289

Gage MJG (2003) Evolutionary biology-scramble for the eggs. Nature 426:22-23

Gage MJG, Cook PA (1994) Sperm size or numbers-effects of nutritional stress upon eupyrene and apyrene sperm production strategies in the moth Plodia interpunctella (Lepidoptera, Pyralidae). Funct Ecol 8:594-599

Gage MJG, Macfarlane CP, Yeates S, Ward RG, Searle JB, Parker GA (2004) Spermatozoal traits and sperm competition in Atlantic salmon: relative sperm velocity is the primary determinant of fertilization success. Curr Biol 14:44-47

Gage MJG, Surridge AK, Tomkins JL, Green E, Wiskin L, Bell DJ, Hewitt GM (2006) Reduced heterozygosity depresses sperm quality in wild rabbits, Oryctolagus cuniculus. Curr Biol 16:612-617

Gomendio M, Cassinello J, Roldan ERS (2000) A comparative study of ejaculate traits in three endangered ungulates with different levels of inbreeding: fluctuating asymmetry as an indicator of reproductive and genetic stress. Proc R Soc Lond B, Biol Sci 267:875-882

Hellriegel B, Blanckenhorn WU (2002) Environmental influences on the gametic investment of yellow dung fly males. Evol Ecol 16:505-522

Hosken DJ, Garner TWJ, Tregenza T, Wedell N, Ward PI (2003) Superior sperm competitors sire higher-quality young. Proc R Soc Lond, B Biol Sci 270:1933-1938

JMP V (1989-2005) In. SAS, Cary, NC

Kilgallon SJ, Simmons LW (2005) Image content influences men's semen quality. Biology Letters 1:253-255 
Kokko H, Rankin DJ (2006) Lonely hearts or sex in the city? Densitydependent effects in mating systems. Philos Trans R Soc Lond B Biol Sci 361:319-334

Kortet R, Taskinen J, Vainikka A, Ylonen H (2004a) Breeding tubercles, papillomatosis and dominance behaviour of male roach (Rutilus rutilus) during the spawning period. Ethology 110:591-601

Kortet R, Vainikka A, Rantala MJ, Myntti J, Taskinen J (2004b) In vitro embryo survival and early viability of larvae in relation to male sexual ornaments and parasite resistance in roach, Rutilus rutilus L. J Evol Biol 17:1337-1344

Kortet R, Vainikka A, Rantala MJ, Taskinen J (2004c) Sperm quality, secondary sexual characters and parasitism in roach (Rutilus rutilus L.). Biol J Linn Soc 81:111-117

Locatello L, Rasotto MB, Evans JP, Pilastro A (2006) Colourful male guppies produce faster and more viable sperm. J Evol Biol 19:1595-1602

Møller AP, Alatalo RV (1999) Good-genes effects in sexual selection. Proc R Soc Lond, B Biol Sci 266:85-91

Müller R (1990) Management practices for lake fisheries in Switzerland. In: van Densen WLT, Steinmetz B, Hughes RH (eds) Management of freshwater fisheries. Pudoc, Wageningen, pp 477-492

Müller G, Ward PI (1995) Parasitism and heterozygosity influence the secondary sexual characters of the European minnow, Phoxinus phoxinus (L) (Cyprinidae). Ethology 100:309-319

Neff BD, Pitcher TE (2005) Genetic quality and sexual selection: an integrated framework for good genes and compatible genes. Mol Ecol 14:19-38

Olsson M, Madsen T, Shine R (1997) Is sperm really so cheap? Costs of reproduction in male adders, Vipera berus. Proc R Soc Lond, B Biol Sci 264:455-459

Parker GA (1990) Sperm competition games - raffles and roles. Proc R Soc Lond, B Biol Sci 242:120-126

Pitcher TE, Neff BD (2006) Genetic quality and offspring performance in Chinook salmon: implications for supportive breeding. Conservation Genetics DOI 10.1007/s10592-006-9204-Z

Pizzari T, Cornwallis CK, Lovlie H, Jakobsson S, Birkhead TR (2003) Sophisticated sperm allocation in male fowl. Nature 426:70-74

Pound N, Gage MJG (2004) Prudent sperm allocation in Norway rats, Rattus norvegicus: a mammalian model of adaptive ejaculate adjustment. Anim Behav 68:819-823

Preston BT, Stockley P (2006) The prospect of sexual competition stimulates premature and repeated ejaculation in a mammal. Curr Biol 16:R239-R241

Ramm SA, Parker GA, Stockley P (2005) Sperm competition and the evolution of male reproductive anatomy in rodents. Proc R Soc Lond, B Biol Sci 272:949-955

Richard M, Lecomte J, de Fraipont M, Clobert J (2005) Age-specific mating strategies and reproductive senescence. Mol Ecol 14:3147-3155

Rubin JF, Perrin N (1990) How does the body-scale model affect back-calculated growth - the example of Arctic charr, Salvelinus alpinus (L), of Lake Geneva (Switzerland). Aquat Sci 52: 287-295

Rudolfsen G, Figenschou L, Folstad I, Nordeide JT, Soreng E (2005) Potential fitness benefits from mate selection in the Atlantic cod (Gadus morhua). J Evol Biol 18:172-179
Rudolfsen G, Figenschou L, Folstad I, Tveiten H, Figenschou M (2006) Rapid adjustments of sperm characteristics in relation to social status. Proc R Soc Lond, B Biol Sci 273:325-332

Snook RR (2005) Sperm in competition: not playing by the numbers. Trends Ecol Evol 20:46-53

Stockley P, Gage MJG, Parker GA, Moller AP (1997) Sperm competition in fishes: the evolution of testis size and ejaculate characteristics. Am Nat 149:933-954

Stoltz JA, Neff BD (2006) Male size and mating tactic influence proximity to females during sperm competition in bluegill sunfish. Behav Ecol Sociobiol 59:811-818

Taborsky M (1998) Sperm competition in fish: 'bourgeois' males and parasitic spawning. Trends Ecol Evol 13:222-227

Tomkins JL, Simmons LW (2002) Mesuring relative investment: a case study of testes investment in species with alternative male reproductive tactics. Anim Behav 63:1009-1016

Urbach D, Bittner D, Lenz TL, Bernet D, Wahli T, Wedekind C (2007) Sperm velocity in an Alpine whitefish: effects of age, size, condition, fluctuating asymmetry, and gonad abnormalities. Journal of Fish Biology 71:672-683

Vladic TV, Jarvi T (2001) Sperm quality in the alternative reproductive tactics of Atlantic salmon: the importance of the loaded raffle mechanism. Proc R Soc Lond, B Biol Sci 268:2375-2381

Vladic TV, Afzelius BA, Bronnikov GE (2002) Sperm quality as reflected through morphology in salmon alternative life histories. Biol Reprod 66:98-105

Wedekind C (1992) Detailed information about parasites revealed by sexual ornamentation. Proc R Soc Lond, B Biol Sci 247:169-174

Wedekind C (1996) Lek-like spawning behaviour and different female mate preferences in roach (Rutilus rutilus). Behaviour 133:681-695

Wedekind C (2002) Sexual selection and life-history decisions: implications for supportive breeding and the management of captive populations. Conserv Biol 16:1204-1211

Wedekind C (2003) Pathogen-driven selection for "good genes" versus genetic variation in small populations. In: Festa-Bianchet $\mathrm{M}$, Apollonio M (eds) Animal behavior and wildlife management. Island, Washington, DC, pp 229-242

Wedekind C, Müller R (2004) Parental characteristics versus egg survival: towards an improved genetic management in the supportive breeding of lake whitefish. Ann Zool Fenn 41:105-115

Wedekind C, Müller R, Spicher H (2001) Potential genetic benefits of mate selection in whitefish. J Evol Biol 14:980-986

Wedekind C, Evanno G, Urbach D, Jacob A, Müller R (2007a) 'Goodgenes' and 'compatible-genes' effects in an Alpine whitefish and the information content of breeding tubercles over the course of the spawning season. Genetica (in press) DOI 10.1007/s10709007-9164-3

Wedekind C, Rudolfsen G, Jacob A, Urbach D, Müller R (2007b) The genetic consequences of hatchery-induced sperm competition in a salmonid. Biol Conserv 137:180-188

Wedell N, Gage MJG, Parker GA (2002) Sperm competition, male prudence and sperm-limited females. Trends Ecol Evol 17:313-320

Wiley ML, Collette BB (1970) Breeding tubercles and contact organs in fishes: their occurance, structure, and significance. Bull Am Mus Nat Hist 143:145-216

Zbinden M, Largiadèr CR, Bakker TCM (2004) Body size of virtual rivals affects ejaculate size in sticklebacks. Behav Ecol 15:137-140 